\title{
Beyond the evidence
}

\section{Duncan Campbell}

The Myth of Heterosexual AIDS: How a Tragedy Has Been Distorted by the Media and Partisan Politics. By Michael Fumento. Basic Books: 1990. Pp. 411. \$22.95.

MICHAEL Fumento's writings and ideas have already made a significant public impact through the pages of the British and US newspapers in which he has argued his controversial case for more than two years. His analysis has been used to criticize general public-health education, to attack the scale and priority of AIDS research funding, and to undermine 'safer sex' education. The publication of his book unhappily coincides with renewed (and ultimately lethal) campaigns intended to assure orthodox heterosexuals that it is safe to have unprotected sex again, and to suggest to governments that they can stop spending money on AIDS because (for the most part) only gays face death.

Fumento is a polemicist, not a scientist. His fundamental hypothesis, only slightly disguised, is that AIDS is necessarily a disease of disgrace, requiring the transmission of both stigma and a virus in order for someone to become infected. Fumento's analysis of HIV transmission is derived from this proposition. Hence, in Fumento's world, heterosexual transmission of HIV cannot and does not occur if the infected partner was himself or herself infected with HIV through heterosexual intercourse. The fact that such transmission is both theoretically predictable from coefficients of transmission measured in partner studies, and is observed epidemiologically - on a particularly large scale in Africa - causes him little discomfort. Where he cannot argue such evidence away by anecdote or by a declamatory sideswipe at "alarmists", he passes on, leaving the rents in the fabric of his argument unpatched.

The true myth of this book - the proposition that heterosexual transmission of the 'pure' sort (which he labels tertiary transmission), cannot occur - is an invention by Fumento. Inevitably, he ties himself in knots. First, he admits that his title is misleading: "The 'myth' of heterosexual AIDS consists of a series of myths, one of which is not that heterosexuals do get it." Fumento then re-asserts his central axiom, and claims that heterosexuals get HIV infection "only from shared needles, from transfusions, from clotting factor, from their mothers at or before birth, and sometimes through sexual intercourse with persons in these categories and with bisexuals" - but never from another heterosexual, infected heterosexually. The axiom is restated again and again: "AIDS will pick off a person here and there in this group [heterosexuals], but the original infected partner will be in one of the two groups in which the disease is epidemic" (my emphasis).

This proposition is untenable and

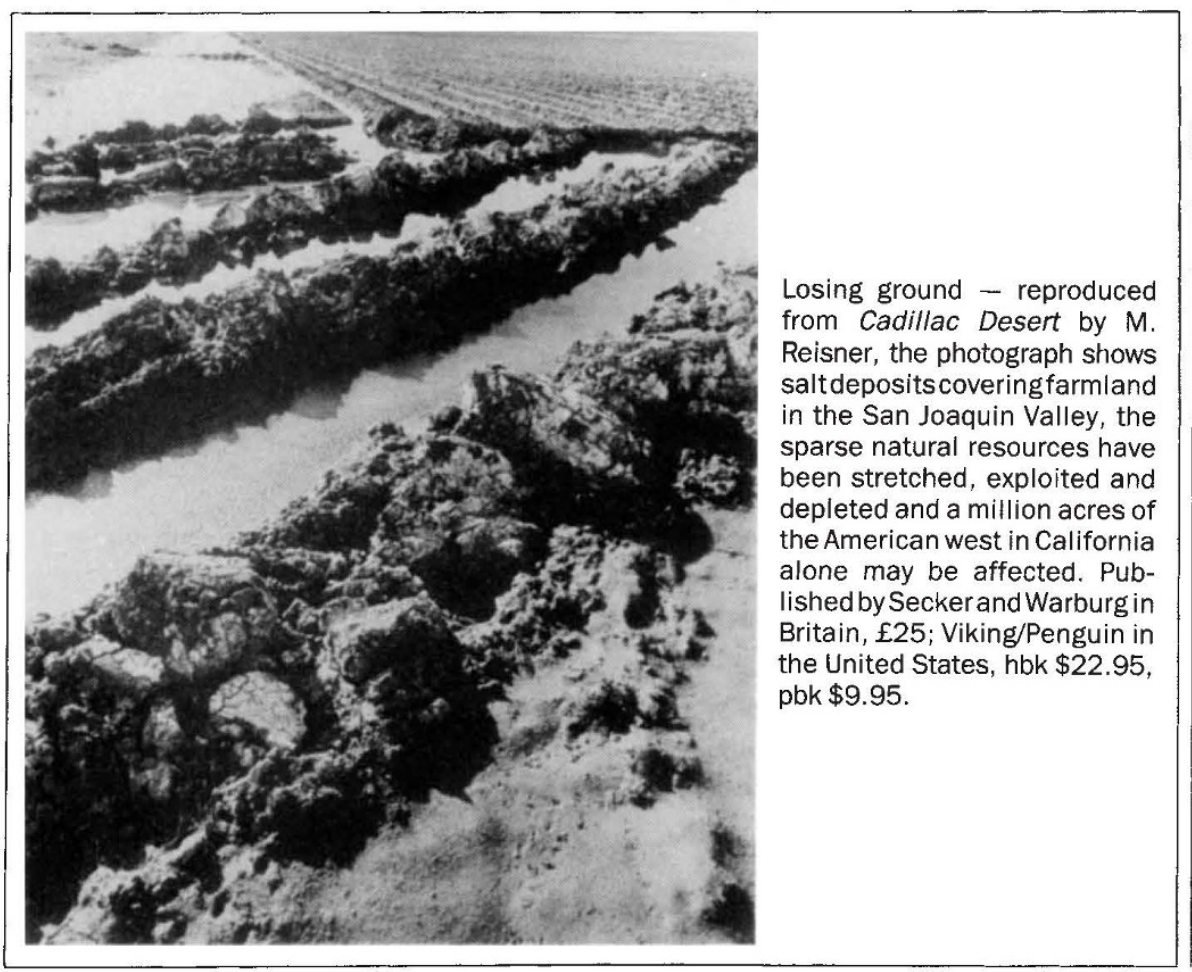

untrue, and the author knows it. Heterosexual men can infect heterosexual women with HIV, he admits, and heterosexual women can infect heterosexual men. Transmission of HIV can occur in a single (penetrative) sexual act. The consequence is of course that HIV can pass sexually from man to woman to man to woman, all heterosexuals. Fumento's axiom is the real myth. He admits this: "There is no physical law saying that tertiary transmission cannot occur."

Fumento goes on to admit that tertiary transmission has been observed, then makes several extraordinary attempts to argue away data showing heterosexual transmission which he finds inconvenient. There is a well-known report, published in 1986, of a Swedish sailor, Lars, found to be the centre of a network of six entirely 'tertiary' cases of heterosexual HIV transmission. "Possible explanations for Lars", writes Fumento, include "an extremely efficient strain of HIV, his proclivity for sex in a manner unusually conducive to HIV transmission" (this is code for anal intercourse) or "a lesson in the laws of probability". By his last option, the author means to suggest that the heterosexual infection of the sailor, three of his subsequent female partners, the husband of one of these women and the child of another was merely a coincidental statistical artefact. According to Fumento's axiom, the sailor - being heterosexual himself cannot transmit HIV to another heterosexual, therefore these other infections are coincidences, not transmission pathways. He rejects the clear and obvious deduction from these and similar data.

It may be thought that anyone whose attitude to empirical evidence is as cavalier as this has little to contribute to public debate except the aggravation of prejudice and ignorance. The one important, substantiated part of Fumento's 400-page tract could have been said in a long footnote elsewhere. This is where Fumento decries some of the more hysterical propagandists who have portrayed AIDS as a new Black Death leading to widespread and general morbidity. The main offenders in this category include such authors as Masters, Johnson and Kolodny, whose text Crisis; Heterosexual Behaviour in the Age of AIDS was published in 1988, and propagandists like Dr. John Seale, who continue to urge the public to fear the possibility of social and/or casual transmission of HIV.

But Fumento's criticism of these writers degenerates into lumping together all those whose views he does not care for, labelling them abusively as "alarmists" or "condomites". In fact, Fumento has much in common with authors like Seale, including a desire to enlarge his reputation for AIDS iconoclasm, and a conservative political agenda in which homophobia plays a major part. 